Tomicic, C. ; Berode, M. Sensitive headspace gas chromatography analysis of free and conjugated 1-methoxy-2-propanol in urine. Analytical and Bioanalytical Chemistry, 396(7):2709-2714, 2010.

\begin{tabular}{|l|l|}
\hline Postprint version & Final draft post-refereeing \\
\hline Journal website & $\underline{\text { http://www.springerlink.com/content/100417 }}$ \\
\hline Pubmed link & $\underline{\text { http://www.ncbi.nlm.nih.gov/pubmed/20155252 }}$ \\
\hline DOI & $\underline{10.1007 / \text { s00216-010-3487-0 }}$ \\
\hline
\end{tabular}




\title{
Sensitive headspace gas chromatography analysis of free and conjugated 1-methoxy-2-propanol in urine
}

\author{
Catherine Tomicic ${ }^{1}$ and Michèle Berode ${ }^{1}$ \\ ${ }^{1}$ Institute for Work and Health, University of Lausanne, 1011 Lausanne, Switzerland
}

\begin{abstract}
Glycol ethers still continue to be a workplace hazard due to their important use on an industrial scale. Currently, chronic occupational exposures to low levels of xenobiotics become increasingly relevant. Thus, sensitive analytical methods for detecting biomarkers of exposure are of interest in the field of occupational exposure assessment.

1-Methoxy-2-propanol (1M2P) is one of the dominant glycol ethers and the unmetabolized urinary fraction has been identified to be a good biological indicator of exposure. An existing analytical method including a solidphase extraction and derivatization before GC/FID analysis is available but presents some disadvantages.

We present here an alternative method for the determination of urinary 1M2P based on the headspace gas chromatography technique. We determined the $1 \mathrm{M} 2 \mathrm{P}$ values by the direct headspace method for 47 samples that had previously been assayed by the solid-phase extraction and derivatization gas chromatography procedure. An intermethod comparison based on a Bland-Altman analysis showed that both techniques can be used interchangeably. The alternative method showed a ten fold lower limit of detection $(0.1 \mathrm{mg} / \mathrm{L})$ as well as good accuracy and precision which were determined by several urinary 1M2P analyses carried out on a series of urine samples obtained from a human volunteer study. The within- and between-run precisions were generally about $10 \%$, which corresponds to the usual injection variability.

We observed that the differences between the results obtained with both methods are not clinically relevant in comparison to the current biological exposure index of urinary 1M2P. Accordingly, the headspace gas chromatography technique turned out to be a more sensitive, accurate and simple method for the determination of urinary $1 \mathrm{M} 2 \mathrm{P}$.
\end{abstract}

Keywords: $\quad$ Biological monitoring - 1-Methoxy-2-propanol - Headspace gas chromatography

\section{Introduction}

Since the 1970s, glycol ethers represent an interesting solvent family for industrial use due to their amphiphile behavior. They can be classified into two groups: ethylene glycol ethers (EGE) and propylene glycol ethers (PGE). Glycol ethers from the ethylenic series were used on a large scale until their reprotoxicity was discovered $[1,2]$. During the last twenty years, a huge work of substitution took place by proposing glycol ethers from the propylenic series. The main difference between these two groups of chemicals lies in their way of biotransformation (see [3] for a good review of the metabolism and the disposition of glycol ethers) .

In humans, EGE are first transformed into 2-alkoxy acetaldehydes by alcohol deshydrogenases, and then into alkoxyacetic acids by aldehyde deshydrogenases, which are metabolites considered responsible for toxicities. PGE exist under the form of two isomers, [3] alpha-isomer and beta-isomer. Alpha-PGE are primarily metabolized through microsomal o-demethylation yielding to relatively non-toxic metabolites of propylene glycol, carbon dioxide and glucuronide as well as sulfate conjugates of the parent compound. In contrast, the $\beta$ isomer, because it is a primary alcohol, is an excellent substrate for alcohol dehydrogenase. Metabolism of the $\beta$ isomer is thus similar to that observed for the ethylene glycol ether series.

1-Methoxy-2-propanol (1M2P), the shorter compound from the propylenic series, is used in a wide variety of industrial and commercial products, primarily water-based paints, varnishes and inks [4-6]. Commercial grade $1 \mathrm{M} 2 \mathrm{P}$ is a mixture of two isomers: the major form being the alpha-isomer $1 \mathrm{M} 2 \mathrm{P}$ and the minor form being the beta-isomer 2-methoxy-1-propanol, which is considered an impurity. 
In spite of some work [7,8] showing the validity of urinary alkoxypropionic acids as biomarker of $1 \mathrm{M} 2 \mathrm{P}$ exposure, the need to analyse unmetabolized 1M2P in urine as free or conjugated products is also becoming more interesting for the exposure assessment $[9,10]$, since the conjugated 1M2P fraction appeared to be between $30 \%$ and $65 \%$ [3]. Moreover, different countries have published a biological exposure index for urinary $1 \mathrm{M} 2 \mathrm{P}$ at the end of the work shift, fixed at $15 \mathrm{mg} / \mathrm{L}$ by the German Research Foundation [11] and $20 \mathrm{mg} / \mathrm{L}$ by the Swiss National Accident Insurance Fund [12].

In the frame of a planned study on mice exposed to 1M2P vapors (unpublished ), our former method [3] has been first modified and then replaced because of its low sensitivity due to small volumes of biological fluids. Thus, there is an obvious need to develop a sensitive, reliable and alternative method.

In this study, a GC headspace injection method is proposed to quantify free and conjugated 1M2P in urine. This analytical method has also been compared to the previous solid-phase extraction-derivatization GC procedure [3] by quantifying urinary $1 \mathrm{M} 2 \mathrm{P}$ in about forty samples of volunteers exposed to $1 \mathrm{M} 2 \mathrm{P}$ using both methodologies. Lastly, our analytical method was validated and applied to the analysis of urine samples collected from volunteers exposed to $1 \mathrm{M} 2 \mathrm{P}$.

\section{Experimental}

\subsection{Chemicals and standards preparation}

1M2P (> 98\%) as analytical standard was obtained from Sigma-Aldrich (Buchs, Switzerland) and tert-butoxy-2propanol as internal standard (IS) from Fluka (Buchs, Switzerland). All other products, anhydrous sodium sulfate, hydrochloric acid and sodium hydroxide were obtained from Merck (Darmstadt, Germany) and were used without further purification. Water was purified through a Millipore treatment system.

The primary stock solutions were prepared by dilution of $50 \mu \mathrm{l}$ of the commercial product in $50 \mathrm{~mL}$ of deionized water to obtain respective concentrations of $0.921 \mathrm{mg} / \mathrm{mL}$ for $\mathrm{M} 2 \mathrm{P}$ and about $1 \mathrm{mg} / \mathrm{mL}$ for tert-butoxy-2propanol used as internal standard.

Working standard of $1 \mathrm{M} 2 \mathrm{P}(18.42 \mu \mathrm{g} / \mathrm{mL})$ was prepared by dilution of $1.0 \mathrm{~mL}$ of the stock solution to $50 \mathrm{~mL}$ of deionized water. For the internal standard, the working solution is diluted 50 fold in deionized water. The stock solutions were kept between $5^{\circ} \mathrm{C}$ and $8^{\circ} \mathrm{C}$ and were stable for at least one month. Working solutions were freshly prepared every day.

\subsection{Equipment}

The apparatus used for the urine analysis was an Agilent 6890 gas chromatograph (Agilent Technologies AG, Urdorf, Switzerland) equipped with a Gerstel Multipurpose Sampler (Gerstel AG, Sursee, Switzerland) operated in headspace mode and with a $2.5 \mathrm{~mL}$ tight gas syringe.

The separation was performed on a CP-Sil $8 \mathrm{CB}$ capillary column $(95 \%$ dimethylpolysiloxane polymer, $5 \%$ phenyl groups; $60 \mathrm{~m}$ x $0.25 \mathrm{~mm}$ i.d., $0.25 \mu \mathrm{m}$ film thickness, Varian Chrompack (Milian SA, Geneva, Switzerland)) using nitrogen as a carrier gas at a constant flow rate of $1.5 \mathrm{~mL} / \mathrm{min}$. The oven temperature was initially held at $90^{\circ} \mathrm{C}$ during 8 minutes, then increased to $250^{\circ} \mathrm{C}$ at $20^{\circ} \mathrm{C} / \mathrm{min}$ and held for 2 minutes. The injector temperature was set at $250{ }^{\circ} \mathrm{C}$ and injection was performed with a split ratio of $10: 1$. The flame ionization detector was set at $250^{\circ} \mathrm{C}$ with an air flow rate of $300 \mathrm{~mL} / \mathrm{min}$, hydrogen flow rate of $30 \mathrm{~mL} / \mathrm{min}$ and a nitrogen makeup flow rate of $30 \mathrm{~mL} / \mathrm{min}$.

The urine sample was kept at a temperature of $95^{\circ} \mathrm{C}$ during 60 minutes in the agitator of the Multipurpose Sampler. The incubation of the samples was performed automatically in the headspace mode, with a correct throughput as the agitator has 6 positions. The syringe temperature was $80^{\circ} \mathrm{C}$ and the injected sample volume was $1000 \mu 1$.

The retention times in these conditions were 6.81 minutes for 1M2P and 11.60 minutes for the internal standard.

\subsection{Calibration and urine samples preparation}

A set of seven $1 \mathrm{M} 2 \mathrm{P}$ calibration points was prepared at the $0,2.30,4.61,6.91,9.21,13.82$ and $18.42 \mathrm{mg} / \mathrm{L}$ levels in water by direct addition in a $20 \mathrm{~mL}$ headspace flask containing $6 \mathrm{~g}$ of $\mathrm{Na}_{2} \mathrm{SO}_{4}$ of $0,250,500,750,1000$, 1500 and $2000 \mu \mathrm{l}$ of the 1M2P working standard solution. The final volume was then adjusted to $2 \mathrm{~mL}$ with deionized water. After the addition of $100 \mu \mathrm{l}$ of the internal standard working solution, the vials were capped.

Two milliliters of human urine and $100 \mu \mathrm{l}$ of internal standard solution were transferred to the $20 \mathrm{~mL}$ headspace vial, screw top, containing $6 \mathrm{~g}$ of $\mathrm{Na}_{2} \mathrm{SO}_{4}$. The vial was rapidly sealed with a PTFE-septum magnetic screw cap. 
To determine the quantity of conjugated $1 \mathrm{M} 2 \mathrm{P}$, an acidic hydrolysis was realized on each urine sample. After the preparation of the calibration points and the samples by the same procedure as above, $200 \mu \mathrm{l}$ of $10 \mathrm{M}$ hydrochloric acid were added to each specimen. Tubes were capped, mixed and incubated at $100^{\circ} \mathrm{C}$ for 16 hours. After allowing specimens to cool to room temperature, the reaction medium was neutralized by addition of 200 $\mu \mathrm{l}$ of $10 \mathrm{M}$ sodium hydroxide. The vials were capped and then ready for the analysis.

The difference in volume $(400 \mu \mathrm{L})$ between the samples without hydrolysis and those with hydrolysis was insignificant in comparison to the volume of the headspace vial $(20 \mathrm{~mL})$. Moreover, the matrix effect was not relevant due to the addition of a large amount of salt.

\section{$2.4 \quad$ Internal quality control}

For assessment of assay precision, urine pools were prepared at two concentrations levels: $1.5 \mathrm{mg} / \mathrm{L}$ and 2.9 $\mathrm{mg} / \mathrm{L}$ for the samples without hydrolysis process and $1.7 \mathrm{mg} / \mathrm{L}$ and $4.9 \mathrm{mg} / \mathrm{L}$ for the samples with hydrolysis process. They were aliquoted and stored at $-20^{\circ} \mathrm{C}$ until used to assay.

\section{Results}

\subsection{Effect of salt addition}

As recommended since 1981 by Sedivec [15] and largely experimented by our team for alcohol determination in urinary samples [16], the addition of a saturating amount $(6 \mathrm{~g})$ of $\mathrm{Na}_{2} \mathrm{SO}_{4}$ has an important effect on the partition coefficient of an alcohol. A single experiment has been carried out, comparing a double set of five 1M2P calibration points without salt to another one with salt. In fact, as illustrated in Fig. 1, the salt addition induced a major increase of the chromatographic signal of compounds of interest with a mean improvement of $7.9 \pm 0.4$ times for 1M2P and for IS. Based on these facts, analysis was performed with salt addition.

\section{Fig. 1}

\subsection{Hydrolysis conditions}

While acidic hydrolysis temperature was kept as in the former method [4], the hydrolysis time has been increased. Indeed, the $1 \mathrm{M} 2 \mathrm{P}$ peak height after 10 hours is nearly a third time higher than the one obtained after 2 hours of incubation. Samples were thus kept at $100^{\circ} \mathrm{C}$ overnight.

In comparison to the analyte, the internal standard has to be a non-endogenous structural analogue and preferably of low toxicity. Tert-butoxy-2-propanol has been identified as the most appropriate internal standard for the method in question. However, the tert-butyl group is easily cleaved off under strongly acidic conditions, particularly if heated, and for this reason, the IS has been added after hydrolysis.

\subsection{Method-to-method comparison}

For method comparison, we determined the urinary 1M2P values by the method proposed here for 47 samples that had previously been assayed by GLC method [3] and stored at $-20^{\circ} \mathrm{C}$ in the meantime. One alternative allowing to affirm if two methods can be used interchangeably or if the new method can replace the existing one is the methodology proposed by Altman and Bland $[13,14]$. The Bland-Altman method permits in our case to determine consistency between two sets of measurements, which are here the urinary $1 \mathrm{M} 2 \mathrm{P}$ concentrations obtained for 47 samples by two different methods [18]. The first step consisted to construct a scatter plot using the direct headspace method (GC-HS method) vs gas chromatography with liquid injection method after solidphase extraction and derivatization (GLC method), with the line of perfect correlation superimposed $(y=x)$. The results are illustrated in Fig. 2 for the urinary 1M2P concentrations determined without hydrolysis only, as the results are similar when hydrolysis takes place.

\section{Fig. 2}

A high correlation does not automatically imply that there is good agreement between the two methods. For this reason, the Altman and Bland methodology proposes to plot a graph by assigning the mean of the two measurements as the abscissa ( $\mathrm{x}$-axis) value, and the difference between the two values as the ordinate (y-axis) value. The Bland-Altman plots are represented on Fig. 3, with the limits of agreement represented by dotted lines 
(mean difference between the two methods \pm 2 standard deviations of the differences). The results illustrated in Fig. 3 correspond to the urinary $1 \mathrm{M} 2 \mathrm{P}$ concentrations determined without hydrolysis only, as the results are similar when hydrolysis takes place.

\section{Fig. 3}

\subsection{Linearity, limit of detection, within- and between-run precision, accuracy}

Calibration standards were prepared and analyzed in duplicate in five independent runs. The calibration curve was constructed using 1M2P/IS peak height ratios vs 1M2P concentration at seven levels in the range 0 to 20 $\mu \mathrm{g} / \mathrm{l}$. The calibration curves were linear over the entire investigated range with a correlation coefficient typically above 0.99 . The analytical limit of detection (LOD) was $0.1 \mathrm{mg} / \mathrm{L}$ estimated from repeated analysis of blank specimens.

A low and a high value for the calibration on one hand and for the internal controls on the other hand have been chosen to represent within- and between-run precision, generally about $10 \%$ which corresponds to the usual injection variability, and accuracy $(99.7-106.4 \%)$ for the determination of urinary 1M2P concentrations. The results are summarized in Tables 1 and 2, without and with hydrolysis process respectively.

\section{Table 1}

\section{Table 2}

\section{Discussion}

The results of our study suggest that urinary $1 \mathrm{M} 2 \mathrm{P}$ can be quantified by a GC headspace injection method, which is especially useful for the assessment of low occupational exposure levels.

For $1 \mathrm{M} 2 \mathrm{P}$, with a vapor pressure of $12 \mathrm{mmHg}(1.60 \mathrm{kPa})$, the headspace technique, as applied to different organic volatiles [15], should be suitable to extract this methoxy alcohol derivative from biological fluid..

In comparison to the existing analytical method [3], several aspects have been improved. The influence of the salt addition on the partition coefficients in gas-water systems with the enrichment of compounds of interest in the "head space" phase is a crucial factor in improving the sensitivity of analysis. The LOD obtained in the described conditions were much lower (10 fold better) than those obtained with the existing method for the determination of urinary 1M2P including a solid-phase extraction and derivatization before GC/FID analysis. With a LOD of $0.1 \mathrm{mg} / \mathrm{L}$, the GC headspace technique allows to determine the target substance in small volumes of biological fluids and/or in low occupational exposures situations.

The method-to-method comparison shows on one hand that the correlation between the measured 1M2P values by both methods seems to be better for the low values as for the higher ones. The fact that there are more samples for the lower values can partly explain this observation. On the other hand, the difference against mean diagram shows that generally, the values are slightly higher for the liquid injection method as for the GC headspace technique. As a good stability of the analyte has been demonstrated by [11] and as the sample preparation is a simple procedure, the important difference in sensitivity of both methods could explain the observed variability in the measurement.

The Bland-Altman plots show that $95 \%$ of the differences obtained between both analytical methods fall within the limits of agreement. Furthermore, we can assume that these differences are not clinically relevant in comparison to the usual biological exposure indices of urinary $1 \mathrm{M} 2 \mathrm{P}$. Thus both methods can be used interchangeably.

The precision of the method, calculated as intra- and inter-day reproducibility, was generally about $10 \%$, which corresponds to the usual injection variability. The difference between theoretical concentration values and the measured one shows a high accuracy. Consequently, the important criteria for the validation of an analytical method are fulfilled.

Another advantage concerns the sample preparation, an uncomplex and short procedure thus limiting possible sources of errors due to manipulation. 
Some limitations of the method exist: it is necessary to avoid the contamination of the urine samples by surrounding solvents or the loss of the analyte during manipulation and analysis.

In summary, we conclude that the determination of urinary 1M2P by the headspace technique is a high sensitive and a particularly simple analytical method, useful in the assessment of low occupational exposure levels to $1 \mathrm{M} 2 \mathrm{P}$. The analytical procedure could be adapted for the determination of other substances of the glycol ethers family as long as physico-chemical properties allow it.

\section{Acknowledgments}

The present work was supported by grants from the French Agency of Environmental and Occupational Health Safety (Afsset), the Swiss Federal Office of Public Health (FOPH) and the National Research Fund (FNR) in Luxembourg. We also want to express our thanks to Ms C. Arnoux for her skillful technical assistance.

\section{References}

[1] A. Cicolella, Glycol ethers: a ubiquitous family of toxic chemicals: a plea for REACH regulation. Ann N Y Acad Sci 1076, 784-789 (2006).

[2] J. E. Doe, Further studies on the toxicology of the glycol ethers with emphasis on rapid screening and hazard assessment. Environ Health Perspect 57, 199-206 (1984).

[3] A. Devanthery, A. Dentan, M. Berode and P. O. Droz, Propylene glycol monomethyl ether (PGME) occupational exposure. 1. Biomonitoring by analysis of PGME in urine. Int Arch Occup Environ Health 73, 311-315 (2000).

[4] A. Dentan, A. Devanthery, J. E. de Peyer and P. O. Droz, Propylene glycol monomethyl ether (PGME) exposure. 2. Identification of products containing PGME, their importance and their use in Switzerland. Int Arch Occup Environ Health 73, 349-351 (2000).

[5] M. K. Hansen, M. Larsen and K. H. Cohr, Waterborne paints. A review of their chemistry and toxicology and the results of determinations made during their use. Scand J Work Environ Health 13, 473-485 (1987).

[6] U. Ulfvarson, R. Alexandersson, M. Dahlqvist, U. Ekholm, B. Bergstrom and J. Scullman, Temporary health effects from exposure to water-borne paints. Scand J Work Environ Health 18, 376-387 (1992).

[7] A. Devanthery, M. Berode, P. O. Droz and J. Pulkkinen, Propylene glycol monomethyl ether occupational exposure (PGME). 4. Analysis of 2-methoxypropionic acid in urine. Int Arch Occup Environ Health 76, 151-155 (2003).

[8] J. Laitinen, Biomonitoring of technical grade 1-alkoxy-2-propanol acetates by analysing urinary 2-alkoxypropionic acids. Sci Total Environ 199, 31-39 (1997).

[9] J. Laitinen, J. Liesivuori and H. Savolainen, Biological monitoring of occupational exposure to 1-methoxy-2-propanol. J Chromatogr B Biomed Sci Appl 694, 93-98 (1997).

[10] K. Jones, D. Dyne, J. Cocker and H. K. Wilson, A biological monitoring study of 1methoxy-2-propanol: analytical method development and a human volunteer study. Sci Total Environ 199, 23-30 (1997). 
[11] C. f. t. I. o. H. H. o. C. C. i. t. W. A. Deutsche Forschungsgemeinschaft, List of MAK and BAT Values 2008, pp. 165-177, Wiley-VCH, Weinheim 2008.

[12] SUVA, Valeurs limites d'exposition aux postes de travail 2009, Lucerne, 2009.

[13] J. M. Bland and D. G. Altman, Statistical methods for assessing agreement between two methods of clinical measurement. Lancet 1, 307-310 (1986).

[14] S. W. Looney, Statistical Methods for Assessing Biomarkers. In Biostatistical Methods. pp. 81-109, 2001.

[15] V. Sedivec, M. Mraz and J. Flek, Biological monitoring of persons exposed to methanol vapours. Int Arch Occup Environ Health 48, 257-271 (1981).

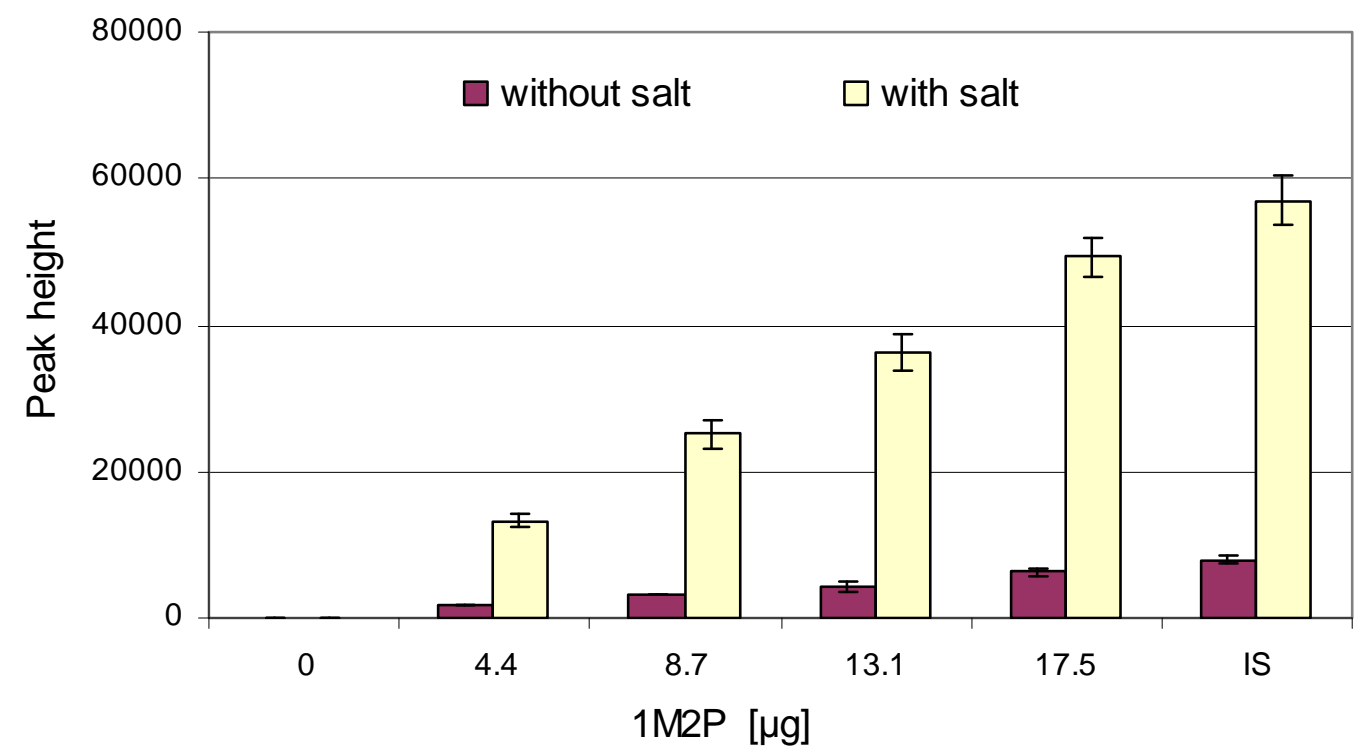

Fig. 1 Effect of addition of saturating amount ( $6 \mathrm{~g}$ ) of $\mathrm{Na}_{2} \mathrm{SO}_{4}$ on spiked urine samples (calibration points) on the chromatographic response of $1 \mathrm{M} 2 \mathrm{P}$ at different levels and on the signal of tert-butoxy-2-propanol used as internal standard (IS). 


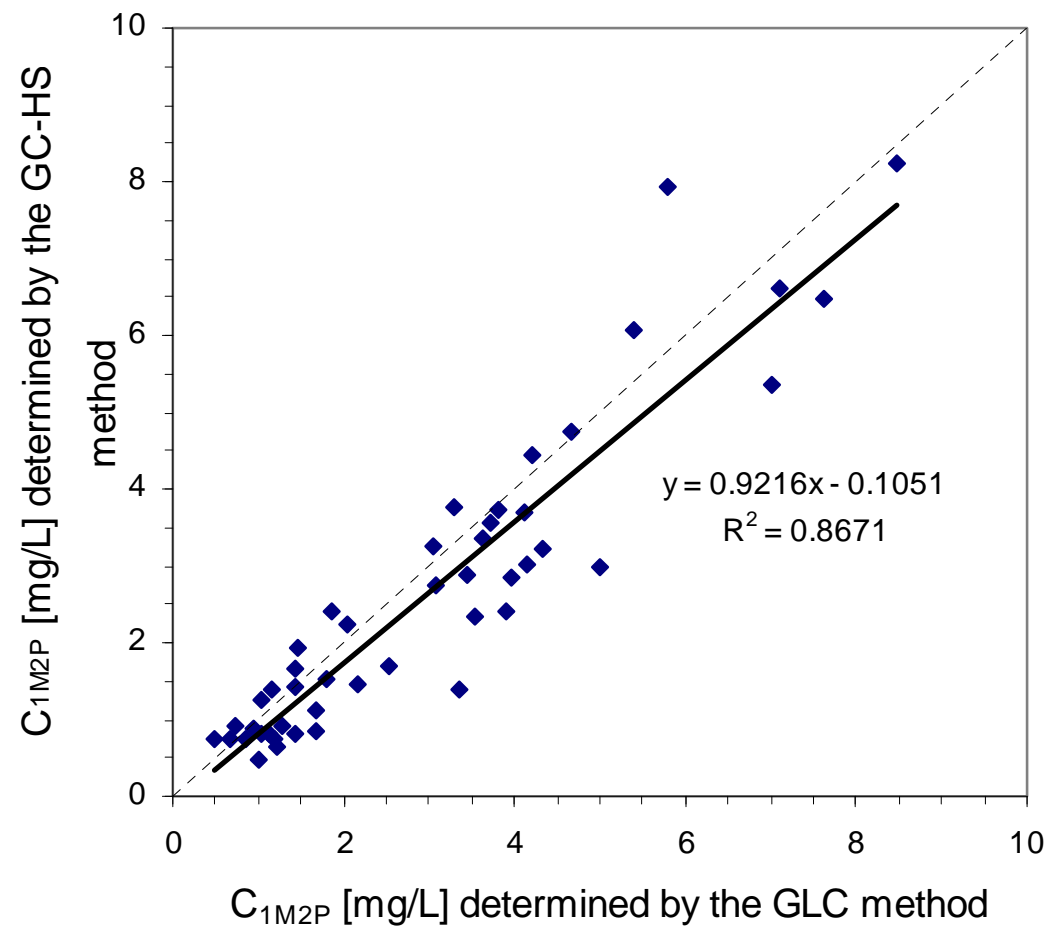

Fig. 2 Scatter plot of $1 \mathrm{M} 2 \mathrm{P}$ concentrations $\left(\mathrm{C}_{1 \mathrm{M} 2 \mathrm{P}}\right)$ determined without hydrolysis using the direct headspace method (GC-HS method) vs gas-chromatography with liquid injection method after solid-phase extraction and derivatization (GLC method [4]), with the line of perfect correlation superimposed ( $\mathrm{y}=\mathrm{x})$ represented by dotted lines

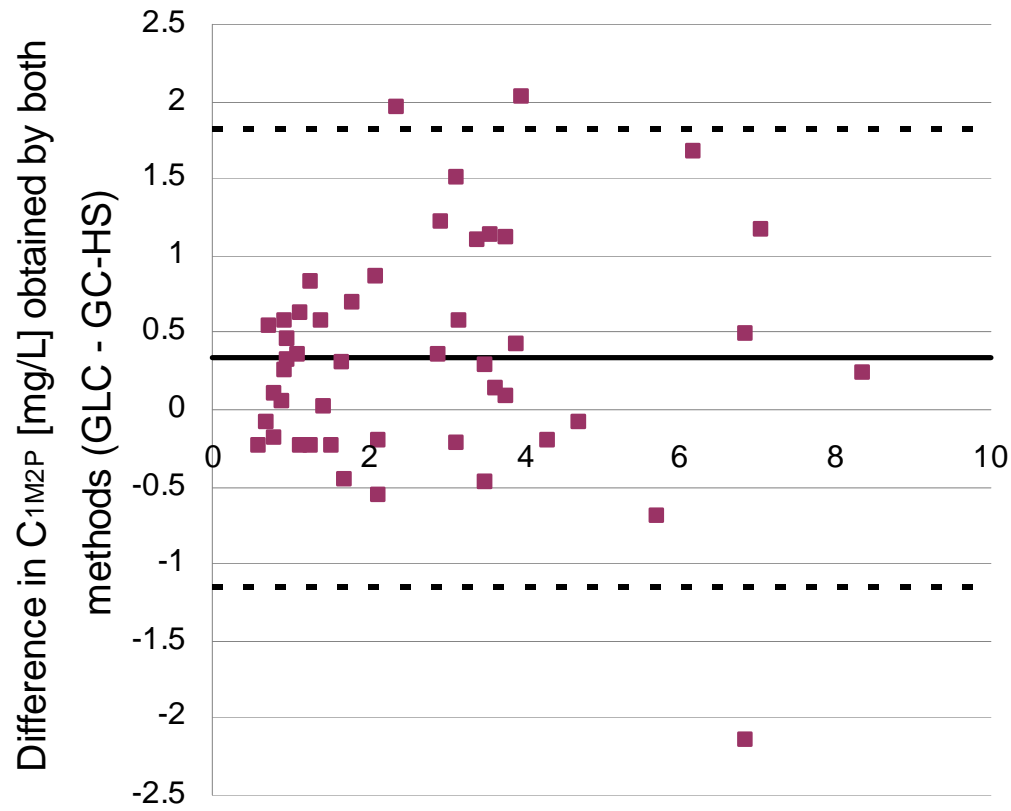

Average in $\mathrm{C}_{1 \mathrm{M} 2 \mathrm{P}}[\mathrm{mg} / \mathrm{L}]$ obtained by both methods (GLC - GC-HS)

Fig. 3 Plot of difference vs mean (Bland-Altman plots) of $1 \mathrm{M} 2 \mathrm{P}$ concentrations $\left(\mathrm{C}_{1 \mathrm{M} 2 \mathrm{P}}\right)$ determined without hydrolysis using the direct headspace method (GC-HS method) and gas-chromatography with liquid injection 
method after solid-phase extraction and derivatization (GLC method [4]), with the limits of agreement represented by dotted lines (mean difference between the two methods \pm 2 standard deviation of the differences)

Table 1 Within-run and between-run precisions and accuracy for the determination of the free urinary 1M2P by the headspace gas chromatography technique; they are represented by several 1M2P analyses carried out on a low and a high value of $1 \mathrm{M} 2 \mathrm{P}$, for the calibration on one hand and for the internal controls on the other hand.

\begin{tabular}{|c|c|c|c|c|c|}
\hline & & \multicolumn{4}{|c|}{ 1M2P theoretical concentrations } \\
\hline & & \multicolumn{2}{|c|}{ Calibration points } & \multicolumn{2}{|c|}{ Internal controls } \\
\hline & & $2.0[\mathrm{mg} / \mathrm{L}]$ & $10.0[\mathrm{mg} / \mathrm{L}]$ & $1.5[\mathrm{mg} / \mathrm{L}]$ & $2.9[\mathrm{mg} / \mathrm{L}]$ \\
\hline \multirow{3}{*}{ Run 1} & Mean $(N=4)$ & 2.185 & 10.038 & 1.438 & 2.993 \\
\hline & $\mathrm{CV} \% *$ & 1.8 & 5.0 & 10.5 & 8.1 \\
\hline & $\%$ Theoretical & 109.3 & 100.4 & 98.5 & 103.2 \\
\hline \multirow[t]{3}{*}{ Run 2} & Mean $(N=4)$ & 2.342 & 10.067 & 1.435 & 2.935 \\
\hline & $\mathrm{CV} \% *$ & 6.4 & 2.8 & 9.1 & 2.3 \\
\hline & $\%$ Theoretical & 117.1 & 100.7 & 98.3 & 101.2 \\
\hline \multirow[t]{3}{*}{ Run 3} & Mean $(N=4)$ & 2.061 & 10.081 & 1.660 & 2.988 \\
\hline & $\mathrm{CV} \% *$ & 15.6 & 3.4 & 7.4 & 10.3 \\
\hline & $\%$ Theoretical & 103.1 & 100.8 & 113.7 & 103.0 \\
\hline \multirow[t]{3}{*}{ Run 4} & Mean $(N=4)$ & 1.920 & 10.100 & 1.288 & 2.693 \\
\hline & $\mathrm{CV} \% *$ & 8.8 & 14.0 & 8.7 & 14.7 \\
\hline & $\%$ Theoretical & 96.0 & 101.0 & 88.2 & 92.8 \\
\hline \multirow[t]{3}{*}{ Overall } & Mean $(N=16)$ & 2.127 & 10.0 .71 & 1.455 & 2.902 \\
\hline & $\mathrm{CV} \% * *$ & 11.2 & 7.0 & 12.4 & 9.7 \\
\hline & $\%$ Theoretical $* * *$ & 106.4 & 100.7 & 99.7 & 100.1 \\
\hline
\end{tabular}


* Within-run precision

** Between-run precision

*** Accuracy

with $\mathrm{N}=$ number of samples

$\mathrm{CV}=$ coefficient of variation 
Table 2 Within-run and between-run precisions and accuracy for the determination of the total urinary $1 \mathrm{M} 2 \mathrm{P}$ by the headspace gas chromatography technique; they are represented by several 1M2P analyses carried out on a low and a high value of $1 \mathrm{M} 2 \mathrm{P}$, for the calibration on one hand and for the internal controls on the other hand.

\begin{tabular}{|c|c|c|c|c|c|}
\hline & & \multicolumn{4}{|c|}{ 1M2P theoretical concentration } \\
\hline & & \multicolumn{2}{|c|}{ Calibration points } & \multicolumn{2}{|c|}{ Internal controls } \\
\hline & & $2.0[\mathrm{mg} / \mathrm{L}]$ & $10.0[\mathrm{mg} / \mathrm{L}]$ & $1.7[\mathrm{mg} / \mathrm{L}]$ & $4.9[\mathrm{mg} / \mathrm{L}]$ \\
\hline \multirow[t]{3}{*}{ Run 1} & Mean $(N=4)$ & 1.790 & 10.186 & 1.533 & 4.613 \\
\hline & $\mathrm{CV} \% *$ & 5.1 & 4.9 & 6.3 & 1.5 \\
\hline & $\%$ Theoretical & 89.5 & 101.9 & 90.1 & 94.9 \\
\hline \multirow[t]{3}{*}{ Run 2} & Mean $(N=4)$ & 2.066 & 10.544 & 1.675 & 5.063 \\
\hline & $\mathrm{CV} \% *$ & 12.7 & 7.8 & 7.5 & 5.2 \\
\hline & $\%$ Theoretical & 103.3 & 105.4 & 98.5 & 104.2 \\
\hline \multirow[t]{3}{*}{ Run 3} & Mean $(N=4)$ & 1.955 & 10.192 & 1.728 & 4.873 \\
\hline & CV\%* & 10.4 & 7.4 & 10.8 & 10.1 \\
\hline & $\%$ Theoretical & 97.7 & 101.9 & 101.6 & 100.3 \\
\hline \multirow[t]{3}{*}{ Run 4} & Mean $(N=4)$ & 2.209 & 10.712 & 1.845 & 4.873 \\
\hline & CV\%* & 8.2 & 11.1 & 6.6 & 12.3 \\
\hline & $\%$ Theoretical & 110.5 & 107.1 & 108.5 & 100.3 \\
\hline \multirow[t]{3}{*}{ Overall } & Mean $(N=16)$ & 2.005 & 10.409 & 1.695 & 4.855 \\
\hline & $\mathrm{CV} \% * *$ & 11.7 & 7.7 & 10.0 & 8.3 \\
\hline & $\%$ Theoretical*** & 100.2 & 104.1 & 99.7 & 99.9 \\
\hline
\end{tabular}

\footnotetext{
with $\mathrm{N}=$ number of samples $\mathrm{CV}=$ coefficient of variation
}

* Within-run precision

** Between-run precision

*** Accuracy 